\title{
Statement of the Spanish Society of Allergology and Clinical Immunology on Provocation Tests With Aspirin/Nonsteroidal Anti-inflammatory Drugs
}

\author{
Izquierdo-Domínguez $\mathrm{A}^{1,2}$, Bobolea I3, Doña I,5, Campo $\mathrm{P}^{4,5}$, Segura $\mathrm{C}^{6}$, Ortega $\mathrm{N}^{7}$, González $\mathrm{R}^{8}$, \\ Delgado $\mathrm{J}^{6}$, Torres $\mathrm{MJ}^{4,5}$, Dordal $\mathrm{MT}^{9}$, on behalf of the SEAIC Rhinoconjunctivitis Committee
}

\author{
${ }^{1}$ Allergy Service, Consorci Sanitari de Terrassa, Barcelona, Spain \\ ${ }^{2}$ Allergy Unit, Clínica Diagonal, Barcelona, Spain \\ ${ }^{3}$ Allergy Section, Servei de Pneumologia i Al.lèrgia Respiratòria, Hospital Clínic, Barcelona, Spain \\ ${ }^{4}$ Allergy Unit, Hospital Regional Universitario de Málaga, Málaga, Spain \\ ${ }^{5}$ Allergy Research Group, Instituto de Investigación Biomédica de Málaga-IBIMA, Málaga, Spain \\ ${ }^{6} U G C$ Alergología, Hospital Universitario Virgen Macarena, Sevilla, Spain \\ ${ }^{7}$ Allergy Unit, Hospital Universitario de Gran Canaria Dr. Negrin, Las Palmas de Gran Canaria, Spain \\ ${ }^{8}$ Allergy Service, Hospital Universitario de Canarias, Tenerife, Spain \\ ${ }^{9}$ Allergy Unit, Servei de Medicina Interna, Hospital Universitari de Bellvitge, Barcelona, Spain
}

J Investig Allergol Clin Immunol 2020; Vol. 30(1): 1-13

doi: 10.18176/jiaci.0449

\section{Abstract}

Nonsteroidal anti-inflammatory drugs (NSAIDs) are widely used throughout the world. They are frequently involved in hypersensitivity reactions, which range from local or mild reactions to systemic and severe reactions. Consequently, it is necessary to perform an exhaustive study of patients in order to make an accurate diagnosis, search for safe procedures in the case of severe reactions, and identify alternative treatment options. Various guidelines and protocols address the management of hypersensitivity to NSAIDs, although these vary widely from country to country. The Committees of Asthma, Rhinoconjunctivitis, and Drug Allergy of the Spanish Society of Allergy and Clinical Immunology (SEAIC) propose the present position statement on available options for provocation testing with aspirin/NSAIDs. This document is the fruit of an exhaustive review of current evidence and is based on recent publications addressing the diagnosis of patients with hypersensitivity to NSAIDs and on a consensus-oriented discussion among a group of experts from the SEAIC. The main objective was to draft an easy-toread, practical guideline for health care professionals in specialist areas who assess and manage patients with suspected hypersensitivity to NSAIDs. Furthermore, indications, contraindications, and procedures for oral, bronchial, and nasal provocation tests with aspirin/NSAIDs have been updated.

Key words: AERD. Aspirin. NSAID. NERD. Aspirin provocation test.

\section{Resumen}

Los antiinflamatorios no esteroideos (AINE) son medicamentos ampliamente utilizados a nivel mundial y frecuentemente implicados en reacciones de hipersensibilidad que pueden comprender desde reacciones locales y/o leves a reacciones sistémicas y graves. La complejidad del diagnóstico ante la falta de pruebas cutáneas o de laboratorio estandarizadas y/o validadas, hace que en muchos casos debamos realizar pruebas de provocación de alto riesgo. Por ello, es necesario un exhaustivo estudio de estos pacientes en los que tienen gran importancia el correcto diagnóstico y la búsqueda de procedimientos más seguros ante pacientes con reacciones graves, así como también la búsqueda de opciones alternativas de tratamientos antiinflamatorios.

Actualmente existen diversas guías y protocolos de actuación que describen el manejo de la hipersensibilidad a los AINE aunque con importante variabilidad entre diferentes países. Desde los distintos comités de Asma, Rinoconjuntivitis y Alergia a Fármacos de la Sociedad Española de Alergología e Inmunología Clínica (SEAIC) proponemos un documento de posicionamiento sobre las opciones en las pruebas de provocación con aspirina/ AINE. Este documento es el resultado de una revisión exhaustiva de la evidencia actual, basada en publicaciones recientes sobre el diagnóstico de pacientes con hipersensibilidad a AINE, y de la discusión consensuada de un grupo de expertos de la SEAIC. El objetivo fundamental ha sido elaborar una guía práctica de fácil lectura dirigida a profesionales sanitarios de atención especializada implicados en el estudio y manejo de pacientes con sospecha de hipersensibilidad a AINE. Además, se ha realizado una actualización sobre las indicaciones, contraindicaciones y procedimientos de las pruebas de provocación oral, bronquial y nasal con aspirina/AINE.

Palabras clave: EREA. Aspirina. AINE. NERD. Provocación con aspirina. 


\section{Introduction}

Nonsteroidal anti-inflammatory drugs (NSAIDs) induce a wide range of adverse reactions associated with their pharmacological properties. NSAIDs are the drugs most frequently involved in hypersensitivity reactions [1,2]. Aspirin (acetylsalicylic acid) was the first synthetic compound marketed with antipyretic, analgesic, and anti-inflammatory activity. Dozens of compounds with similar activity were subsequently developed, all of them capable of inducing hypersensitivity reactions in susceptible persons. The reactions vary according to their latency period (immediate or delayed), organ involved (skin, respiratory tract, other), and severity (from rhinitis to bronchospasm, exanthema or urticaria, and anaphylaxis) [3].

Diagnosis of hypersensitivity reactions is complex because we do not have skin tests or in vitro tests that are sufficiently reliable or standardized. Consequently, in most cases we must perform provocation tests.

The objective of the present position statement is to set out a practical guideline on the performance of oral, bronchial, and nasal provocation tests in patients with suspected hypersensitivity to NSAIDs.

Therefore, the members of the respective Asthma, Rhinoconjunctivitis, and Drug Allergy Committees of SEAIC held face-to-face and online meetings to harmonize working criteria. Group leaders were then chosen to review the data. A systematic methodology was followed to obtain data sources and draft content. The literature search strategy was based on the following key words: allergy to aspirin/NSAIDs, hypersensitivity, L-ASA, bronchial challenge test, oral and nasal challenge test. The searches were performed based on the OVID Medline, EMBASE, and Cochrane Review databases using Boolean operators. The scientific assays selected were evaluated in terms of their quality and risk of error following the criteria of the Oxford Centre for Evidencebased Medicine [http://www.cebm.net/index.aspx=1025]. Our research identified a total of 458 studies. Only studies in English were included. Finally, 104 papers were eligible for systematic review.

\section{Classification of Hypersensitivity Reactions to NSAIDs}

Hypersensitivity reactions to NSAIDs can be classified into 2 key groups based on their underlying mechanism: (1) allergic reactions mediated by specific immunological mechanisms (selective hypersensitivity, immunoglobulin [Ig] E in immediate reactions or $\mathrm{T}$ cells in delayed reactions), in which patients present reactions to a single NSAID or several NSAIDs of the same chemical group; and (2) hypersensitivity reactions not mediated by a specific immunological mechanism (the most common), in which the mechanism is associated with the enzyme cyclo-oxygenase (COX)-1, with the result that the patient reacts to various NSAIDs belonging to different chemical groups [3]. In this case, inhibition of COX-1 leads to an increase in the expression of specific proinflammatory mediators such as cysteinyl-leukotrienes (cys-LT) and prostaglandin $[\mathrm{PG}] \mathrm{D}_{2}$ and a decrease in the expression of other bronchoprotective agents such as $\mathrm{PGE}_{2}$, thus generating an imbalance that eventually triggers symptoms (bronchospasm, nasal symptoms, skin symptoms) [4].

\subsection{Allergic Reactions to NSAIDs}

These are selective reactions induced by a single NSAID or several NSAIDs belonging to the same chemical group, with no cross-reactivity between groups. They are COX-independent and are classified into 2 groups:

a) Immediate reactions, which usually appear in $<4-5$ hours. The most frequent symptoms are urticaria/ angioedema or anaphylaxis.

b) Nonimmediate reactions, which generally appear 24-48 hours after administration of the drug and manifest as skin symptoms (generalized exanthema, fixed drug eruption), involvement of other organs (eg, hypersensitivity pneumonitis or aseptic meningitis), or severe adverse cutaneous reactions (StevensJohnson syndrome, toxic epidermal necrolysis, acute generalized exanthematous pustulosis, drug-induced hypersensitivity syndrome).

\subsection{Hypersensitivity reactions to NSAIDs not mediated by a specific immunological mechanism}

These are the most common type and result from crossreactivity between different NSAIDs that are not structurally related [5]. According to the position statement published by the European Academy of Allergy and Clinical Immunology [3], these reactions can be classified into 3 groups:

a) NSAIDs-exacerbated respiratory disease (NERD), which manifests mainly as bronchial obstruction, dyspnea, cough, wheezing, nasal congestion, sneezing and rhinorrhea. NERD affects patients with underlying chronic respiratory disease of the lower and/or upper airways (asthma/chronic rhinosinusitis with/without sinonasal polyposis [CRSwNP/CRSwoNP]).

b) NSAIDs-exacerbated cutaneous disease (NECD), which manifests as urticaria and/or angioedema that affects patients with a history of spontaneous chronic urticaria.

c) NSAIDs-induced urticaria/angioedema (NIUA), which manifests as urticaria and/or angioedema in persons with no history of spontaneous chronic urticaria or underlying respiratory disease. These patients are generally atopic and sensitized mainly to house dust mite (Dermatophagoides pteronyssinus and Dermatophagoides farinae). The most characteristic manifestation is palpebral angioedema [6].

\section{Pathophysiology}

Hypersensitivity reactions to NSAIDs are caused by various pathogenic mechanisms (see above)

Allergic reactions are not associated with COX-1 inhibition, and patients show good tolerance to NSAIDs from other groups, including potent COX-1 inhibitors. Symptoms are associated with production of specific $\operatorname{IgE}$ in terms of symptoms, reaction time (generally $<1$ hour), and reaction to a specific NSAID or several NSAIDs from 
the same pharmacological group, with good tolerance to the rest. This IgE-mediated mechanism has been proven with pyrazolones [7,8] and, in some cases, with paracetamol [9], although skin test or in vitro test results are only occasionally positive with other drugs [10]. In delayed organ-specific and cutaneous reactions, sensitization to drugs is mediated by specific $\mathrm{T} \mathrm{CD}^{+}$and $\mathrm{CD}^{+}$lymphocytes [11]. This mechanism has been reported in sporadic cases with pyrazolones and aryl acetic and propionic acid agents $[5,12,13]$.

Nonimmune hypersensitivity reactions have received the most attention, especially in patients with asthma and urticaria/ angioedema. Blockade of COX and, more specifically, its constitutive isoform COX-1, in susceptible individuals seems to play a key role in hypersensitivity reactions to NSAIDs [14].

The main biological activity of NSAIDs is that of inhibiting production of inflammatory mediators resulting from metabolism of arachidonic acid (AA). AA is metabolized via 3 pathways for production of inflammatory mediators: (1) via the enzyme COX, leading to production of PG; (2) via 5-lipoxygenase (5-LOX), leading to the production of leukotrienes (LT); and (3) via 12-lipoxygenase (12-LOX), leading to production of 12-hydroxyeicosatetraenoic acid (12-HETE) and lipoxins [15].

In most cells, except for platelets and endothelial cells, $\mathrm{PGE}_{2}$ is the main product of COX-1 and COX-2. When synthesis of $\mathrm{PGE}_{2}$ is suppressed by inhibition of COX-1 in epithelial and inflammatory cells in the airways, the negative feedback effect on 5-LOX disappears, and, consequently, a large quantity of cys-LT is synthesized and released. In parallel, the density of cys-LT receptors increases on bronchial smooth muscle, vascular endothelial cells, eosinophils, and sinonasal and bronchial epithelial cells, thus amplifying the pharmacological and proinflammatory effects of these eicosanoids [16]. Therefore, a sudden decrease in synthesis of $\mathrm{PGE}_{2}$ seems to be the main precipitating event in overproduction of LT, with the subsequent reaction in the respiratory tract. In fact, exogenous inhalation of $\mathrm{PGE}_{2}$ prevents the bronchoconstriction caused by aspirin and inhibits urinary excretion of cys-LT [17].

In patients with CRSwNP who are hypersensitive to NSAIDs, expression of the type 2 receptor of $\mathrm{PGE}_{2}$ in the mucosa [18] and in polyp samples is diminished [19]. Therefore, abnormal receptor expression in these patients could reduce the antiproliferative and anti-inflammatory capacity of $\mathrm{PGE}_{2}$. Similarly, production of $\mathrm{PGE}_{2}$ by bronchial fibroblasts in asthmatics who are hypersensitive to NSAIDs is also less pronounced than in tolerant asthmatics [4]. In addition, production of $9 \alpha, 11 \beta-\mathrm{PGF}_{2}$, a metabolite of $\mathrm{PGD}_{2}$, is excessive, with higher levels of the metabolite and more frequent bronchial symptoms in the serum of patients with NERD than in patients with nasal symptoms only [20].

As for LTs, in patients with NERD, inhibition of COX is associated with increased synthesis and release of cys-LT, with the base form containing 2 to 10 -fold more $\mathrm{LTE}_{4}$ in urine than in aspirin-tolerant asthmatics [21]. Exposure to aspirin in patients with NERD leads to very significantly increased secretion of $\mathrm{LTE}_{4}$ in urine [22] and in both the sinonasal mucosa [23] and the bronchial mucosa [24]. A recent meta-analysis showed that $\mathrm{LTE}_{4}$ in urine can be considered a marker of NERD and potentially useful as a clinical test for identifying the risk of hypersensitivity to NSAIDs in patients with asthma [25].
In summary, there are specific differences between patients with NERD and aspirin-tolerant asthmatics with respect to the levels of most eicosanoids. The pathogenic mechanisms of NERD seem to be associated with a complex imbalance in AA, more specifically with the metabolism of prostanoids and cys-LT. Such dysregulations in the degradation of AA are genetically determined. Hypersensitivity to NSAIDs and its clinical manifestations are the result of an interaction between genetic and environmental factors.

Although NECD is the most frequent form of hypersensitivity to NSAIDs, most genetic studies have focused on NERD; therefore, the studies generally have a limited number of patients. Furthermore, most studies have focused on polymorphisms associated with the metabolic pathway of AA, and 3 genome-wide association studies have been published [26]. The polymorphism of the LTC4 synthase gene $(-444 \mathrm{~A}>\mathrm{C})$ has been associated with a greater risk of NERD [27] and increased expression of the gene in eosinophils, bronchial mucosa, and nasal mucosa. However, this association has not been confirmed in American or Asian populations [26]. Similarly, increased expression of $-444 A>C$ has been reported in patients with NERD [28], although not in Spanish patients with NECD [29]. Furthermore, 2 variants in the COX-1 genes (rs5789 and rs10306135) were recently shown to be associated with NERD [30].

These phenomena have received less attention in patients with cutaneous manifestations. In patients with NECD, excretion of $\mathrm{LTE}_{4}$ in urine is more pronounced after oral provocation with aspirin than in tolerant patients with chronic urticaria, whose extension is associated with levels of LTE $_{4}$ in urine [31]. However, a different pattern has been found for eicosanoids in patients with NECD: nasal lavage after specific provocation with lysine-aspirin did not reveal an increase in $\mathrm{PGD}_{2}, \mathrm{LTD}_{4}$, or $\mathrm{LTE}_{4}$, which did increase in patients with NERD [32].

\section{Classification of Controlled Provocation Tests With Aspirin}

Given that the underlying mechanism of a reaction is not immunological, but rather a consequence of inhibition of COX-1, skin testing is of no use in cases of hypersensitivity reactions to multiple NSAIDs. In most cases, controlled exposure will be necessary to ensure an appropriate diagnosis.

Before starting a provocation test, it is necessary to determine whether the patient is likely to have selective allergy or hypersensitivity to multiple NSAIDS; therefore, we must know whether 1 or several NSAIDs are involved. In addition to enabling us to predict the underlying pathogenic mechanism, this information helps us to design an action plan. Therefore, it is very important to ensure that the clinical history is as accurate as possible.

Depending on the route of administration, we can distinguish between 4 types of provocation test: oral, bronchial (inhaled), nasal, and intravenous. Only the first 3 are used in daily clinical practice. Intravenous provocation testing is used exclusively in Japan [33].

Controlled oral provocation testing with aspirin is considered the "gold standard" for diagnosis of hypersensitivity 
to NSAIDs [34]. However, it is very time-consuming, and potential systemic reactions can prove very severe, especially in patients with NERD, in whom the risk of severe bronchospasm has led to the development of techniques that are less likely to cause a systemic reaction. These include bronchial provocation testing and nasal provocation testing, which are faster and safer and prove particularly useful when oral challenge testing is contraindicated.

\subsection{Oral Provocation Testing With Aspirin}

\subsubsection{Introduction}

Controlled oral provocation testing is the main tool for diagnosis and the only unanimously accepted diagnostic method that makes it possible to identify patients with exclusively cutaneous symptoms [34].

\subsubsection{Indications}

The indications are well established: (1) for confirming or ruling out a diagnosis of hypersensitivity to the culprit drug in patients for whom there are no other conclusive allergology tests; and (2) provocation with a drug other than that which produced the reaction, generally aspirin, in order to confirm or rule out cross-reactivity between NSAIDs [34].

Additional indications include the following [34,35]:

a) Providing a safe alternative therapy in cases of confirmed hypersensitivity.

b) The need to perform desensitization to aspirin for therapeutic purposes.

c) The study of real prevalence of sensitization to aspirin.

d) Investigation of the underlying basic pathogenic mechanisms in this type of reaction.
Despite these indications, performance of controlled provocation tests is highly controversial. Some authors recommend them, whereas others do not, since they believe that the risk of triggering severe anaphylactic reactions is high. Therefore, it seems reasonable to evaluate the individual patient carefully before performing an oral provocation test $[35,36]$.

\subsubsection{Contraindications}

The main contraindications are as follows [34,36]:

a) Patients with severe or unstable respiratory disease $\left(\mathrm{FEV}_{1}\right.$ varying by more than $20 \%$ ).

b) A history of anaphylactic reaction may be a contraindication for performance of oral provocation testing with the drug involved.

c) Organ-specific conditions (hepatitis, meningitis) and severe cutaneous reactions (this group does not include maculopapular rash or fixed drug eruption).

d) Patients who do not sign the informed consent to undergo provocation testing.

e) Patients with a respiratory infection or uncontrolled chronic condition, such as asthma or urticaria.

f) Patients with psychiatric disorders that affect performance of the oral provocation test.

g) Patients with a disease in which NSAIDs and/or epinephrine are contraindicated and patients who cannot interrupt treatment with betablockers to undergo the test (relative contraindication).

\subsubsection{Methodology}

- Preparation: The test should be performed under the supervision of experienced health professionals and at centers with the necessary equipment to treat

Table 1. Recommendations for Interrupting Treatment That May Interfere With the Performance of Oral Provocation Tests With Aspirin and Bronchial/ Nasal Challenge Tests With Lysine-Aspirin [33,48]

\begin{tabular}{|c|c|c|}
\hline \multicolumn{2}{|l|}{ Oral Provocation Test and Bronchial Challenge Test } & \multirow{2}{*}{$\begin{array}{l}\text { Nasal Provocation Test } \\
\text { Time of avoidance before nasal } \\
\text { exposure to lysine-aspirin }\end{array}$} \\
\hline Medication & $\begin{array}{l}\text { Time of avoidance before oral exposure } \\
\text { to aspirin }\end{array}$ & \\
\hline Oral/topical antihistamines & $3 \mathrm{~d}$ & $\begin{array}{l}48 \mathrm{~h} \text { or } 1-2 \text { wk depending on } \\
\text { the drug/ } 4-5 \text { days }\end{array}$ \\
\hline Leukotriene receptor antagonists & $7 \mathrm{~d}$ & \\
\hline Oral corticosteroids & $\begin{array}{l}\text { If the patient is receiving regular treatment } \\
\text { with oral corticosteroids, the dose should } \\
\text { not exceed } 10 \mathrm{mg} \text { of prednisolone or equivalent }\end{array}$ & $2-3 w k$ \\
\hline Intranasal/inhaled corticosteroids & $\begin{array}{l}\text { Maintain the lowest dose possible in a stable } \\
\text { fashion throughout the provocation test }\end{array}$ & $\begin{array}{l}48-72 \mathrm{~h} / \text { suspension is not } \\
\text { necessary }\end{array}$ \\
\hline Long-acting beta-agonists & $24-48 \mathrm{~h}$ & \\
\hline Short-acting beta-agonists & $6-8 \mathrm{~h}$ & \\
\hline Long-acting anticholinergics & $7 \mathrm{~d}$ & \\
\hline Monoclonal antibodies (omalizumab especially) & 5 half-lives of the drug ( $6 \mathrm{mo}$ in the case of omal & izumab) \\
\hline Nasal decongestants (in general) & & $2 \mathrm{~d}$ \\
\hline $\begin{array}{l}\text { Tricyclic antidepressants/reserpine } \\
\text { or clonidine-type antihypertensive agents }\end{array}$ & & $3 \mathrm{wk} / 3 \mathrm{wk}$ \\
\hline
\end{tabular}


severe systemic reactions [33,34,37-39]. The patient must sign a written informed consent document before undergoing the test $[33,39,40]$ and must be stable, with well-controlled asthma (baseline $\mathrm{FEV}_{1}$ must be at least 60\%$70 \%$ of predicted and more than $1.5 \mathrm{~L}$ [absolute]) $[33,34]$. It has been suggested that LT receptor antagonists, corticosteroids (inhaled and oral), long-acting $\beta_{2}$-agonists and long-acting muscarinic antagonists reduce the risk of bronchospasm in oral and bronchial provocation testing without altering naso-ocular reactions [41-44]. Moreover, new evidence shows that omalizumab reduces or eliminates aspirin intolerance in treated patients $[45,46]$. Although no data are available to date, new biologicals targeting anti-IL-5/IL-5 receptors might also modify the results of aspirin provocation testing [47]; therefore, we believe that aspirin provocation tests should either not be performed or be carefully interpreted in patients receiving biologicals. In summary, and in line with current European guidelines, this document recommends avoiding some drugs before performing the tests $[36,48]$ (see also Table 1).

- Procedure: The oral provocation test should be performed in a simple-blind, placebo-controlled fashion, although it should be double-blind in situations where psychological aspects play a role [39]. Both aspirin and placebo are administered in gel capsules; these should be identical in appearance if possible. The capsules should be prepared by the hospital pharmacy in order to prevent subjective interpretations by the patient [33]. Patients should be monitored continuously (baseline and at 30- to 60-minute intervals), and symptoms, $\mathrm{FEV}_{1}$, arterial blood pressure, heart rate, and peak nasal inspiratory flow (PNIF) should be recorded. Other methods of objective evaluation of nasal obstruction that can be used include active anterior rhinomanometry and acoustic rhinometry $[37,39]$. The option of inserting a venous line can be evaluated in specific cases [33,37].

On the first day of the test, we administer 3 capsules of placebo at intervals of 90-120 minutes. $\mathrm{FEV}_{1}$ should not vary by more than $15 \%$ during the test; if it does, the patient's condition is considered unstable, resulting in suspension of the test. On the second and third days, we administer increasing doses of aspirin until signs or symptoms indicative of a reaction appear (positive provocation) or the maximum dose of aspirin is reached (negative provocation) [37]. The doses and intervals at which the capsules are administered vary from study to study (Table 2). If the patient has a history of severe reaction to aspirin or other NSAIDs or has a high risk of bronchial reaction during exposure (previous history of visiting the emergency department for asthma and/or baseline $\mathrm{FEV}_{1}<80 \%$ ), then the test should be started with lower doses of aspirin [33,49] (Table 2). As for the intervals between doses, most studies indicate that the capsules should be administered at intervals of 90 and 180 minutes $[33,38,40]$. However, it has been suggested that intervals of 60 minutes are safe in patients who experience immediate reactions to NSAIDs [50]. There have been no extensive evaluations of whether protocols with shorter intervals between doses are associated with more severe reactions, since the observation time was not sufficiently long to enable identification of a reaction before the following dose was administered. In protocols with intervals of 180 minutes, the reactions appear a mean of 102 minutes after a mean cumulative dose of aspirin of $68 \mathrm{mg}$ [49,51]. However, when the interval is 60 minutes, the reactions appear a mean of 50 minutes after a mean cumulative dose of 157 mg of aspirin [50].

\subsubsection{Interpretation of the results}

We must determine whether there are bronchial symptoms (bronchospasm, chest tightness, wheezing), nasal symptoms (rhinorrhea, nasal congestion), ocular symptoms (tearing, conjunctival injection), cutaneous symptoms (edema, erythema, urticarial), or other symptoms (nausea, abdominal pain). A positive result in an oral provocation test, which should be interrupted immediately, is defined as the appearance of 1 or more of the following signs/symptoms [33,37]:

a) Decrease in $\mathrm{FEV}_{1}>20 \%$ over baseline value.

b) Objective signs and symptoms of respiratory reaction (rhinorrhea, nasal congestion, sneezing fits, wheezing,

Table 2. Protocols for Oral Provocation Testing With Aspirin

\begin{tabular}{lll}
\hline Protocol & Interval Between Doses, min & Dose of Aspirin, mg \\
\hline Scripps Clinic [38] & 180 & 1 st day: 20-40, 40-60, 60-100 \\
& & 2 nd day: 100-160, 160-325, 325 \\
Aspirin Desensitization Joint Task Force [40] & 90 & $20.25,40.5,81,162.5,325$ \\
University of Texas Southwestern [33] & 60 & $40,81,120,162,325^{\mathrm{b}}$ \\
EAACI guideline [33] & $90-120$ & $27,44,117,312,500^{\mathrm{c}}$ \\
Spanish Society of Allergy and Clinical & 180 & 1 st day: $50-100$ \\
Immunology Guideline [34] & & 2 st day: $250-500$
\end{tabular}

alf the patient has a history of attending the emergency department for asthma and/or baseline FEV ${ }_{1}$, the first test should be with the lowest dose possible of aspirin (20 or $30 \mathrm{mg}$ ).

bIf the patient has a history of serious reactions to nonsteroidal anti-inflammatory drugs, the protocol should be started with $20 \mathrm{mg} 60 \mathrm{minutes}$ before the dose of $40 \mathrm{mg}$.

If the patient has a history of severe reaction to aspirin or other nonsteroidal anti-inflammatory drugs, divide the first dose of aspirin (27 mg) into 2 doses (10 mg and $17 \mathrm{mg}$ ), which should be administered at an interval of 90-120 minutes. 
tearing, cough, chest tightening, stridor, dysphonia) or extrabronchial symptoms (angioedema, wheals, erythema, abdominal pain, nausea, vomiting), even if $\mathrm{FEV}_{1}$ does not decrease $>20 \%$ over baseline.

In patients with NERD, most positive oral provocation tests (90\%-98\%) include naso-ocular reaction, and 35\%-90\% of cases bronchial reaction [49,50,52,53]. Gastrointestinal, cutaneous, and laryngeal symptoms appear in $23 \%, 10 \%$, and $8 \%$ of cases, respectively [52]. Hypotension has been reported sporadically $[43,54]$.

The result of an oral provocation test is defined as negative when the maximum cumulative dose of aspirin is reached without signs, symptoms, or reaction and with no decrease in $\mathrm{FEV}_{1}>20 \%$ over baseline.

\subsubsection{Complications and their management}

The severity of a previous NSAID-induced reaction reported by the patient cannot predict the reaction observed during oral provocation testing with aspirin, which is generally milder [52]. Severe bronchial reactions (defined as a decrease in $\mathrm{FEV}_{1}>30 \%$ over baseline) have been associated with the following factors:

a) Unstable asthma during the provocation test [55].

b) Not taking LT receptor antagonists during the provocation test [49].

c) Severe asthma (baseline $\mathrm{FEV}_{1}<80 \%$ predicted and history of visits to the emergency department for asthma) [49].

d) Elevated levels of $\mathrm{LTE}_{4}$ in urine [55] (test not available in daily clinical practice) [49].

e) Age at the time of the oral provocation test (30-40 years) [49].

f) Less than 10 years since the last reaction [49].

If 3 or more of these factors are present, the risk of a moderate to severe reaction during the provocation test with aspirin is $43 \%$ [49]. In the case of a positive reaction, treatment should be administered early. Naso-ocular reactions should be treated with oral and topical antihistamines, mast cell stabilizers, and nasal decongestants. Bronchial reactions should be treated with short-acting $\beta_{2}$-agonists until $\mathrm{FEV}_{1}$ returns to $90 \%$ of baseline. Oral or parenteral corticosteroids should be administered in the case of more severe reactions. Laryngeal reactions should be managed with nebulized or intramuscular epinephrine. Cutaneous symptoms should be managed with oral or parenteral $\mathrm{H}_{1}$ antihistamines, and gastrointestinal symptoms with oral or intravenous $\mathrm{H}_{2}$ antihistamines [54]. Anaphylactic reactions must be managed with intramuscular epinephrine and according to the protocol recommended by current guidelines [54,56-58].

\subsubsection{Special situations}

- Pediatric patients: NSAIDs are the most commonly prescribed drugs in pediatric medicine, whether as antipyretic, anti-inflammatory, or analgesic agents. Therefore, it is necessary to make the correct diagnosis in the case of suspected hypersensitivity reaction. Diagnosis in children is complex, since childhood fever is caused by both bacterial and viral infections, which can progress with cutaneous symptoms that mimic an allergic reaction. A study performed in Spain showed that specific nonimmunological reactions are the most common in children. Ibuprofen is the most frequently involved drug, angioedema the most frequently reported condition, and controlled oral provocation the most reliable diagnostic method [59]. In pediatric patients, prescription of authorized drugs is limited by the patient's age. Paracetamol is the preferred oral antipyretic agent, and high-dose ibuprofen and paracetamol the preferred anti-inflammatory/analgesic agents. Other authorized drugs include naproxen, diclofenac, metamizole, and indomethacin. Meloxicam has also been used in children aged 2-12 years and is authorized for use in patients with rheumatic conditions such as juvenile rheumatoid arthritis. Treatment with aspirin has become considerably less frequent in recent years [59] owing to reports of Reye syndrome. Notwithstanding, even though aspirin is not recommended as an antipyretic drug, it does continue to be used as a pediatric antiplatelet drug or for the treatment of other diseases, such as Kawasaki syndrome [60].

Few parenteral NSAIDs have been authorized for use in children in Spain. With the exception of dipyrone and paracetamol, the remaining injectable intravenous solutions have not been assessed in children or in adolescents. Therefore, the safety and efficacy profile has not been established, and the drug cannot be recommended as such on the summary of product characteristics, although dexketoprofen/ trometamol, for example, is prescribed [61].

As is the case in adults, diagnostic algorithms based solely on the clinical history have low positive and negative predictive values, are of little worth, and can never replace an allergology work-up consisting of skin tests (when a selective reaction is suspected) and controlled oral provocation, which is considered the gold standard [62].

Indications and contraindications, as well as the methodology and techniques used in controlled oral provocation tests in adults, can almost be generalized to children, with some slight variations. As in adults, there are several protocols, which differ in the following respects:

a) The dosage used.

b) The number of doses administered: most authors reach the total cumulative dose in 4 steps [36], although this number could be lower if the reaction is not very indicative.

c) The interval between doses. This is generally set at 30 minutes, although some authors increase the dose gradually every 60-90 minutes until they reach the total cumulative dose, which is adjusted for age and weight [36,63-65].

The drug is most commonly administered as a syrup or suspension. The criteria for a positive result are similar to those applied for adults.

- Pregnancy: Analgesics are one of the most commonly used drug types during pregnancy, and paracetamol is the drug of choice for mild to moderate pain. NSAIDs should be used with caution, especially during the last trimester $[66,67]$. Most authors consider pregnancy a contraindication for oral provocation testing with NSAIDs. However, in specific situations, such as the immediate need for antiplatelet medication, a 
provocation test may be necessary after evaluating the cost-benefit ratio. The United States Food and Drug Administration classifies aspirin at antiplatelet doses (75-162 mg/d) as category D for pregnancy, and treatment should only be administered in specific cases after evaluation of the cost-benefit ratio [68]. In cases where antiplatelet medication is fully indicated during pregnancy, such as in antiphospholipid syndrome, the patient should be desensitized to aspirin after taking all necessary precautions: admission to an intensive care unit and presence of a multidisciplinary team (allergologist, anesthetist, gynecologist, and, on occasion, neonatologist) $[69,70]$.

- Other diseases: In other risk situations, such as kidney failure, heart disease, and liver disease, controlled oral provocation testing should be considered a high-risk procedure and performed on an individual basis only after considering the risk-benefit ratio.

\subsection{Bronchial Provocation Testing With Lysine-Aspirin}

\subsubsection{Introduction}

Oral provocation testing has been compared with bronchial provocation testing in 3 studies [71-73]. The results reported were similar. Both methods have the same specificity (around 93\%), although oral provocation is more sensitive ( $89 \%$ vs $77 \%$ ) [71]. Therefore, as the negative predictive value of bronchial testing is lower, a negative result should be followed by an oral provocation test in order to obtain the definitive diagnosis [33].

\subsubsection{Indications}

Patients over 18 years with suspicion of NERD who present with bronchial symptoms after taking NSAIDs.

\subsubsection{Contraindications}

The contraindications are basically those of spirometry itself (eg. recent surgery, aneurisms) as well as severe or poorly controlled asthma during the previous month, severe diseases (heart, digestive, liver, or kidney), respiratory infection during the 4 weeks before the provocation test, pregnancy, and treatment with betablockers.

\subsubsection{Methodology}

- Preparation [33,36]: The patient must sign a written informed consent document before undergoing bronchial provocation. The patient's usual medication should be stopped (Table 1).

- Procedure: Bronchial provocation is performed with lysine-aspirin, a salt of aspirin that is more water-soluble than aspirin ( $40 \%$ vs $0.3 \%)$, less irritant, and better tolerated for inhalation. The technique was first described in 1977 by Bianco et al [74] and then modified by Phillips et al in 1989 [75]. The current protocol is based on a modified Philips method [33]. It can be performed by means of continuous inhalation at incremental volumes with a constant output [76] or intermittent breathing through a nebulizer connected to an electronic dosimeter (eg, Me-Far or Spira-Electro 2) [77].
Table 3. Protocol for Inhaled Provocation Testing With Lysine-Aspirin Using a Dosimeter [33]

\begin{tabular}{lccc}
\hline $\begin{array}{l}\text { Concentration of } \\
\text { Lysine-Aspirin, } \\
\text { mg/mL }\end{array}$ & $\begin{array}{c}\text { No. of } \\
\text { Inhalations }\end{array}$ & $\begin{array}{c}\text { Dose of } \\
\text { Lysine-Aspirin } \\
\text { Inhaled, mg }\end{array}$ & $\begin{array}{c}\text { Cumulative } \\
\text { Dose of } \\
\text { Lysine-Aspirin, } \\
\text { mg }\end{array}$ \\
\hline 45 & 1 & 0.405 & \\
45 & 5 & 2.025 & 2.43 \\
90 & 5 & 4.05 & 6.48 \\
180 & 5 & 8.1 & 14.58 \\
180 & 10 & 16.2 & 30.78 \\
360 & 10 & 32.4 & 63.18 \\
360 & 20 & 64.8 & 127.98 \\
\hline
\end{tabular}

Bronchial provocation testing is performed on an outpatient basis. The technique is carried out by suitably trained nursing staff under the supervision of the allergologist. According to the recommendations of current clinical guidelines, the medication necessary to treat potential reactions must be at hand (shortacting $\beta_{2}$-agonists and anticholinergic drugs, inhaled and systemic corticosteroids, epinephrine, antihistamines, nasal vasoconstrictors).

The test is started with baseline spirometry to verify that $\mathrm{FEV}_{1}$ is $>70 \%$ predicted and $>1.5 \mathrm{~L}$. The test cannot be performed if this requirement is not fulfilled.

The patient first receives 5 inhalations of the control diluent (physiologic saline $0.9 \%$ ). Spirometry is repeated at 10 minutes. A decrease of $>10 \%$ in $\mathrm{FEV}_{1}$ is considered a sign of airway instability that could generate a false-positive result; therefore, the test should be postponed. If $\mathrm{FEV}_{1}$ does not decrease by more than $10 \%$ over baseline, the test continues and the $\mathrm{FEV}_{1}$ recorded with the diluent is the reference value.

Fresh lysine-aspirin solutions (Inyesprin, Aristo Pharma Iberia, S.L.) are prepared immediately before the test (900 mg of lysine-aspirin is equivalent to $500 \mathrm{mg}$ of aspirin). First, 2 vials are diluted with $5 \mathrm{~mL}$ of distilled water to produce a solution of $360 \mathrm{mg} / \mathrm{mL}$, which is equivalent to $200 \mathrm{mg} / \mathrm{mL}$ of aspirin. Successive dilutions are then made with saline solution $0.9 \%$ to obtain concentrations of $180 \mathrm{mg} / \mathrm{mL}$ and $45 \mathrm{mg} / \mathrm{mL}$. Consecutive doses of lysine- aspirin are inhaled every 30 minutes, and spirometry and peak expiratory flow (PEF) values are measured at 10,20, and 30 minutes after each dose (Table 3 ).

Once the provocation test is completed, irrespective of whether the result is positive or negative, additional spirometry testing and determination of PEF should be performed in the clinic at 1 hour and 2 hours after the test. The patient subsequently records PEF every 2 hours at home, except while sleeping, until 24 hours after the test, when he/she returns to the clinic with the PEF recording.

\subsubsection{Interpretation of the results}

The criteria for a positive bronchial provocation are as follows $[33,73,78]$ :

a) Immediate reaction with bronchospasm and decrease in $\mathrm{FEV}_{1} \geq 20 \%$. 
b) Immediate reaction with a $15-20 \%$ decrease in $\mathrm{FEV}_{1}$, as well as extra-bronchial symptoms (sneezing, naso-ocular pruritus, nasal congestion, runny nose, conjunctival reddening and pruritus, tearing, and palpebral angioedema).

c) Dual reaction: immediate and late reaction.

d) Exclusively late reaction (late decrease in PEF $\geq 20 \%$, between 4 and 24 hours after the provocation test).

The result of the bronchial provocation is considered negative if the maximum dose is reached with no decrease in $\mathrm{FEV}_{1}$ or $\mathrm{PEF} \geq 20 \%$ up to the 24 hours following the end of the test. In order to clarify the diagnosis in this case, oral provocation with aspirin is scheduled after an interval of at least 7 days $[33,36,39]$.

\subsubsection{Complications and management}

a) Bronchospasm must be treated with nebulized salbutamol, as needed, in order to relieve symptoms.

b) Nasal obstruction can be treated with a topical nasal decongestant (eg, oxymetazoline). If untreated, nasal obstruction can lead to trapping of secretions and severe headache. Nasal symptoms can also be managed with oral antihistamines.

c) Ocular symptoms can be treated with oral antihistamines.

d) Laryngospasm must be treated with intramuscular epinephrine.

\subsubsection{Special situations:}

Pediatric patients: Bronchial provocation is contraindicated in patients aged under 18 years; therefore, when NERD is suspected, diagnosis must be confirmed based on oral provocation with aspirin, as set out in the corresponding section of this consensus document.

\subsection{Nasal Provocation Test With Lysine-Aspirin}

\subsubsection{Introduction}

While a large number of studies have addressed the standardization of oral and bronchial provocation testing with aspirin, fewer studies have analyzed nasal provocation, despite the fact that it is a safe alternative to oral provocation and bronchial provocation in the assessment of patients with hypersensitivity to NSAIDs. Nasal provocation testing was implemented in daily clinical practice at the end of the 1970 s and 1990 s, both for provocation tests with allergens/ drugs and for the study of the response to treatment, as well as for study of the immunology and pathophysiology of the

Table 4. Diagnostic Yield of Challenge Tests With Aspirin

\begin{tabular}{lccc} 
Type of Test & Sensitivity & Specificity & $\begin{array}{c}\text { Negative } \\
\text { Predictive Value }\end{array}$ \\
\hline Oral & $89 \%$ & $93 \%$ & $77 \%$ \\
Bronchial & $77 \%$ & $93 \%$ & $64 \%$ \\
Nasal & $80 \%$ & $90 \%$ & $78 \%$
\end{tabular}

nasal mucosa. Guidelines and consensus statements on the methodology and diagnostic use of nasal provocation have been published [79-89]. The diagnostic usefulness of nasal provocation and bronchial provocation compared with oral provocation is summarized in Table 4.

The nasal provocation test involves reproducing a response in the nasal mucosa with controlled exposure to the drug (using lysine-aspirin, as in bronchial provocation). The response is characterized by nasal obstruction, rhinorrhea, and edema of the nasal mucosa, with increased airflow resistance. Airflow resistance can be measured objectively using 2 techniques: rhinomanometry (RNM) and acoustic rhinometry (ARM) (see below). In addition, the patient's symptoms can be evaluated subjectively during nasal provocation test using a visual analog scale and symptom scores (rhinorrhea, sneezing, nasal obstruction, and pruritus).

One of the main limitations of this diagnostic method results from its low sensitivity and, therefore, its low negative predictive value. Therefore, a history that is suggestive of NERD and a negative result in a nasal provocation test with lysine-aspirin still require confirmatory oral provocation.

However, if we consider the yield of this approach and its ability to identify conjunctival symptoms, it should be considered the method of choice in patients who report analgesic-induced naso-ocular symptoms.

\subsubsection{Indications}

Nasal provocation is indicated in the study of patients with suspected NERD and, more specifically, in those whose concomitant conditions prevent them from undergoing oral or bronchial provocation as, for instance, in patients with $\mathrm{FEV}_{1}$ $<70 \%$ (see above).

\subsubsection{Contraindications}

Nasal provocation should not be performed in the following cases:

- Massive nasal polyposis

- Perforated septum

- Autoimmune diseases (eg, Wegener disease, ChurgStrauss syndrome)

- Immunodeficiency

- Pregnancy

- Uncontrolled severe asthma

- Concomitant respiratory infection

- Age under 5 years

\subsubsection{Methodology}

\subsubsection{Preparation (preconditions)}

i. Patient-related conditions

- The patient must sign a written informed consent document before undergoing nasal provocation.

- The patient must be asymptomatic, that is, if the patient also has another type of rhinitis such as allergic or infectious rhinitis, then the test should be performed outside the pollen season or, in the case of perennial allergens, when mild symptoms do not interfere with the results of the test. The test should be postponed 
until at least 2-4 weeks after an exacerbation of allergic or infectious rhinitis $[82,84,85]$.

- The patient must also be free of respiratory symptoms, with no asthma exacerbations or bronchial infections in the previous month at the time of the test. Forced spirometry is always recommended before and after nasal provocation in order to evaluate lung function.

- The patient should avoid smoking and alcohol during the 24-48 hours before the test.

- The provocation should be postponed for 6-8 weeks after nasal surgery [84].

- Where possible, avoid performing nasal provocation during pregnancy.

- Nasal provocation is not recommended in patients with a perforated septum or total nasal obstruction, since objective evaluation of nasal obstruction is very difficult and interpretation of the results more complicated.

- Any medication that can modify the nasal response must be discontinued before the test (Table 1).

ii. Room-related conditions

- Temperature and humidity must be maintained at a constant temperature of $20^{\circ} \mathrm{C}$ to $22^{\circ} \mathrm{C}$ with humidity of $40 \%-60 \%$. Temperatures above $35^{\circ} \mathrm{C}$ with a high degree of humidity $(80 \%-90 \%)$ can alter the immediate response owing to diminished release of histamine and the vascular/neural response [90].

- The patient must be acclimated (20-30 minutes in the room) in order to avoid nonspecific reactions to environmental conditions.

- Nasal provocation testing should preferably be performed in the morning in order to avoid the irritant effect of the usual daily stimulants (eg, tobacco smoke, pollution, spicy food, coffee, exercise).

iii. Conditions related to the staff who carry out the test

- Appropriate knowledge of the test methodology.

- Appropriate knowledge of the technique that will be used to evaluate the results, eg, RNM or ARM.

- Knowledge of and access to the necessary therapeutic measures in the case of a positive result.

\subsubsection{Procedure}

The most widely used approach today is instillation of $0.1 \mathrm{~mL}$ of lysine-aspirin at the head of the inferior turbinate with a syringe, pipette, or dropper. Lysine-aspirin is not available in the USA, where nasal provocation is performed using intranasal ketorolac $[33,91]$. Experience with ketorolac has been reported by Quiralte-Castillo et al [92].

A micropipette is preferred. Doses of lysine-aspirin vary according to the study and are detailed below.

Objective evaluation is usually by active anterior RNM (AARNM) or ARM. RNM enables simultaneous measurement of flow and pressure variations in air current crossing the nostrils during the different phases of respiration. For evaluation of nasal permeability, AARNM with a facemask and computerized recording of pressure, flow and resistance is recommended as the optimal test in daily clinical practice $[93,94]$.

The doses of lysine-aspirin used in nasal provocation with AARNM vary according to the protocol: $20 \mathrm{mg}$ as the maximum cumulative aspirin-equivalent dose [95], a single aspirin-equivalent dose of $14 \mathrm{mg}[96,97]$, and 4 progressive concentrations $(5,25,50$, and $100 \mathrm{mg} / \mathrm{mL})$, with a total cumulative aspirin-equivalent dose of $18 \mathrm{mg}$ [98]. The cumulative dose used is critical for the yield of the test, since low doses do not enable sufficient analytical values to be reached [96], whereas doses above $30 \mathrm{mg}$ of aspirin are irritant and, therefore, invalidate interpretation of the results [97].

ARM is used to evaluate nasal permeability through measurement of areas and volumes in the nasal cavity based on reflection of sound waves through an acoustic rhinometer. It is noninvasive and reproducible and requires only minimal cooperation from the patient. Therefore, it is easy to use with children. It is well standardized for the demonstration of changes in the permeability of the nasal mucosa.

Measurements are made at different time points depending on the method used $[33,98]$. Therefore, we must perform a measurement at baseline, 30 minutes after administration of the diluent, and at 15, 30,60, and 90 minutes after administration of lysine-aspirin. Diluent $(0.9 \% \mathrm{NaCl})$ is administered beforehand in order to rule out nasal hyperreactivity. We then administer $29 \mathrm{mg}$ of lysine-aspirin $100 \mu \mathrm{L}$ (equivalent to $16 \mathrm{mg}$ of aspirin) to the inferior turbinate of each nostril using an Eppendorf pipette $[99,100]$.

\subsubsection{Interpretation}

Nasal provocation with lysine-aspirin performed using ARM is considered positive when nasal cavity volume at $12 \mathrm{~cm}$ decreases by $25 \%$ with respect to the postdiluent value $[98,99]$. Some studies show that the test can be considered positive when there is a fall of $25 \%$ in nasal volume at 2-5 cm [99,100]. Values obtained using ARM should also be correlated with clinical symptoms (subjective values) by means of the visual analog scale (see above) and symptom scores. A positive result is defined as an increase of $30 \%$ of airflow resistance $[90,99,101]$.

The reference values obtained using AARNM are not fully agreed upon, and a certain degree of variability is accepted as a result of differences in the devices used, age, weight, and the racial-ethnic characteristics of the study population $[93,94,100,101]$. A minimum $100 \%$ increase is accepted as a criterion for positivity $[87,101,102]$.

\subsubsection{Complications and management}

If the result of the nasal provocation test is positive, a topical or systemic antihistamine should be administered depending on the intensity of the symptoms. While systemic reactions are extremely rare, any that occur should be treated as stated in the section on oral provocation.

Lastly, the reappearance of nasal symptoms, especially obstruction, at 3 to 12 hours after nasal provocation should be interpreted as a delayed reaction [88]. The patient should be informed of this possibility, and measures must be taken to ensure that appropriate treatment is available for control of symptoms. The criteria for evaluating a delayed nasal response are not as well established as those for bronchial response. Although the immediate response is easy to demonstrate, symptom scoring is not sufficient in the case of a delayed reaction. 


\subsubsection{Special situations}

ARM is easy to perform and reproducible. It requires little cooperation from the patient, thus making it especially useful for children. In addition, it is not affected by rhinorrhea or nasal obstruction. However, ARM cannot be performed in cases of perforated septum. No international consensus regimens have been drafted for nasal provocation. Therefore, criteria for positivity, methodologies, and the preparations used in nasal provocation testing vary depending on the study. Irrespective of these limitations, nasal provocation is a very useful clinical and research tool in nasal disease and for the study of patients with NERD [102,103].

\subsection{Ocular provocation with aspirin}

Ocular symptoms in hypersensitivity reactions to NSAIDs in NERD are unusual and have not been sufficiently documented to date. An exhaustive review of the literature revealed that no publications have explored the possibility of performing provocation tests with aspirin or other NSAIDs (eg, lysine-aspirin, ketorolac) directly on the conjunctiva in humans [104].

\section{Conclusions}

Diagnosis of hypersensitivity to NSAIDs is of great importance for the patient and for the health system. The patient must know not only the NSAIDs to be avoided, but also those that he/she can tolerate. Therefore, provocation tests have become an essential diagnostic tool.

Ideally, priority should be given to nasal and bronchial provocation in patients with NERD (depending on the availability of the technique and the level of knowledge and experience of the treatment team). However, a negative result should be followed by an oral provocation, since this has a higher negative predictive value.

In the case of NECD, neither nasal provocation testing nor bronchial provocation testingappears to be of use. Therefore, oral provocation should be performed.

\section{Funding}

The authors declare that no funding was received for the present study.

\section{Conflicts of Interest}

MTD reports having received personal fees from GSK, AstraZeneca, ALK, Mylan, Allergy Therapeutics, and Diater. These were not associated with the present manuscript.

The other authors declare that they have no conflict of interests.

\section{References}

1. Cornejo-Garcia JA, Blanca-Lopez N, Doña I, Andreu I, Agúndez JA, Carballo M, et al. Hypersensitivity reactions to non-steroidal anti-inflammatory drugs. Curr Drug Metab. 2009;10:971-80.
2. Doña I, Blanca-Lopez N, Torres MJ, Garcia-Campos J, GarciaNuñez I, Gomez F, et al. Drug hypersensitivity reactions: patterns of responses, drug involved and temporal variation in a large series of patients evaluated. J Investig Allergol Clin Immunol. 2012;22:363-71.

3. Kowalski ML, Asero R, Bavbek S, Blanca M, Blanca-Lopez N Bochenek $G$, et al. Classification and practical approach to the diagnosis and management of hypersensitivity to nonsteroidal anti-inflammatory drugs. Allergy. 2013;68:1219-32.

4. Pierzchalska M, Szabó Z, Sanak M, Soja J, SzczeklikA. Deficient prostaglandin E2 production by bronchial fibroblasts of asthmatic patients, with special reference to aspirin-induced asthma. J Allergy Clin Immunol. 2003;111:1041-8.

5. Doña I, Blanca-López N, Cornejo-García JA, Torres MJ, Laguna JJ, Fernández J, et al. Characteristics of subjects experiencing hypersensitivity to non-steroidal anti-inflammatory drugs: patterns of response. Clin Exp Allergy. 2011;41:86-95.

6. Quiralte J, Blanco C, Castillo R, Delgado J, Carrillo T. Intolerance to nonsteroidal antiinflammatory drugs: results of controlled drug challenges in 98 patients. J Allergy Clin Immunol. 1996;98:678-85.

7. Himly M, Jahn-Schmid B, Pittertschatscher K, Bohle B, Grubmayr K, Ferreira F, et al. IgE-mediated immediate type hypersensitivity to the pyrazolone drug propyphenazone. J Allergy Clin Immunol. 2003; 111:882-8.

8. Gómez E, Blanca-López N, Torres MJ, Requena G, Rondón C, Canto $\mathrm{G}$, et al. Immunoglobulin E-mediated immediate allergic reactions to dipyrone: value of basophil activation test in the identification of patients. Clin Exp Allergy. 2009;39:1217-24.

9. Rutkowski K, Nasser SM, Ewan PW. Paracetamol hypersensitivity: clinical features, mechanism and role of specific IgE. Int Arch Allergy Immunol. 2012;159:60-4.

10. Canto MG, Andreu I, Fernández J, Blanca M. Selective immediate hypersensitivity reactions to NSAIDs. Curr Opin Allergy Clin Immunol. 2009;9:293-7.

11. Woesner KM, Castells M. NSAID Single-Drug-Induced reactions. Immunol Allergy Clin North Am. 2013;33:237-49.

12. Posadas SJ, Pichler WJ. Delayed drug hypersensitivity reactions new concepts. Clin Exp Allergy. 2007;37:989-99.

13. Rozieres A, Vocanson M, Said BB, Nosbaum A, Nicolas JF. Role of $T$ cells in nonimmediate allergic drug reactions. Curr Opin Allergy Clin Immunol. 2009;9:305-10.

14. Ortega N, Álvarez MJ, Almeida L, Blanco C, Castillo, GarcíaDumpiérrez $A$, et al. Nimesulida: ¿Una nueva alternativa en pacientes con intolerancia a antiinflamatorios no esteroideos? Rev Esp Alergol Inmunol Clin. 1998;13:195.

15. Vane JR, Bakhle YS, Botting RM. Cyclooxygenase 1 and 2. Annu Rev Pharmacol Toxicol. 1998;38:97-120.

16. Sousa AR, Parikh A, Scadding G, Corrigan CJ, Lee TH. Leukotriene-receptor expression on nasal mucosal inflammatory cells in aspirin-sensitive rhinosinusitis. N Engl J Med. 2002; 347:1493-9.

17. Sestini P,Armetti L, Gambaro G, Pieroni MG, Refini RM, Sala A, et al. Inhaled PGE2 prevents aspirin-induced bronchoconstriction and urinary LTE4 excretion in aspirin sensitive asthma. Am J Respir Crit Care Med. 1996;153:572-5.

18. Ying S, Meng Q, Scadding G, Parikh A, Corrigan CJ, Lee TH. Aspirin-sensitive rhinosinusitis is associated with reduced E-prostanoid 2 receptor expression on nasal mucosal inflammatory cells. J Allergy Clin Immunol. 2006;117:312-8. 
19. Machado-Carvalho L, Torres R, Perez-Gonzalez M, Alobid I, Mullol J, Pujols L, et al. Altered expression and signalling of EP2 receptor in nasal polyps of $A E R D$ patients: role in inflammation and remodelling. Rhinology. 2016 Sep;54:254-65.

20. Swierczynska M, Nizankowska-Mogilnicka E, Zarychta J, Gielicz A, Szczeklik A. Nasal versus bronchial and nasal response to oral aspirin challenge: Clinical and biochemical differences between patients with aspirin-induced asthma/ rhinitis. J Allergy Clin Immunol. 2003;112:995-1001.

21. Sanak M. Eicosanoid Mediators in the Airway Inflammation of Asthmatic Patients: What is New? Allergy Asthma Immunol Res. 2016;8:481-90.

22. Sladek K, Szczeklik A. Cysteinyl leukotrienes overproduction and mast cell activation in aspirin-provoked bronchospasm in asthma. Eur Respir J. 1993;6:391-9.

23. Picado C, Ramis I, Rosellò J, Prat J, Bulbena O, Plaza V, et al. Release of peptide leukotriene into nasal secretions after local instillation of aspirin in aspirin-sensitive asthmatic patients. Am Rev Respir Dis. 1992;145:65-9.

24. Sladek K, Dworski R, Soja J, Sheller JR, Nizankowska E, Oates $J A$, et al. Eicosanoids in bronchoalveolar lavage fluid of aspirin-intolerant patients with asthma after aspirin challenge. Am J Respir Crit Care Med. 1994;149(4Pt1):940-6.

25. Hagan JB, Laidlaw TM, Divekar R, O’Brien EK, Kita H, Volcheck GW. Urinary Leukotriene E4 to Determine Aspirin Intolerance in Asthma: A Systematic Review and Meta-Analysis. J Allergy Clin Immunol Pract. 2017:5:990-7.

26. Cornejo-Garcia JA, Oussalah A, Blanca M, Gueant-Rodriguez RM, Mayorga C, Waton J, et al. Genetic Predictors of Drug Hypersensitivity. Curr Pharm Des. 2016;22:6725-33.

27. Sanak M, Levy BD, Clish CB, Chiang N, Gronert K, Mastalerz L, et al. Aspirin-tolerant asthmatics generate more lipoxins than aspirin-intolerant asthmatics. Eur Respir J. 2000;16:44-9.

28. Mastalerz L, Setkowicz M, Sanak M, SzczeklikA. Hypersensitivity to aspirin: common eicosanoid alterations in urticaria and asthma. J Allergy Clin Immunol. 2004;113:771-5.

29. Torres-Galván MJ, Ortega N, Sánchez-García F, Blanco C, Carrillo T, Quiralte J. LTC4-synthase A-444C polymorphism: lack of association with NSAID-induced isolated periorbital angioedema in a Spanish population. Ann Allergy Asthma Immunol. 2001;87:506-10.

30. Ayuso P, Plaza-Serón MC, Blanca-López N, Doña I, Campo P, Canto $G$, et al. Genetic variants in arachidonic acid pathway genes associated with NSAID-exacerbated respiratory disease. Pharmacogenomics. 2015;16:825-39.

31. Setkowicz $M$, Mastalerz $L$, Podolec-Rubis $M$, Sanak $M$, Szczeklik A. Clinical course and urinary eicosanoids in patients with aspirin-induced urticaria followed up for 4 years. J Allergy Clin Immunol. 2009:123:174-8.

32. Campo P, Ayuso P, Salas M, Plaza MC, Cornejo-García JA, Doña I, et al. Mediator release after nasal aspirin provocation supports different phenotypes in subjects with hypersensitivity reactions to NSAIDs. Allergy. 2013; 68:1001-7.

33. Nizankowska-Mogilnicka E, Bochenek G, Mastalerz L, Swierczyńska M, Picado C, Scadding G, et al. EAACI/GA2LEN guideline: aspirin provocation tests for diagnosis of aspirin hypersensitivity. Allergy. 2007;62:1111-8.

34. Ortega N, Doña I, Moreno E, Audicana MT, Barasona MJ, Berges-Gimeno MP, et al. Practical guidelines for diagnosing hypersensitivity reactions to nonsteroidal anti-inflammatory drugs. J Investig Allergol Clin Immunol. 2014;24:308-23.

35. Ortega Rodríguez NR, Quiralte Enríquez J, Fraj Lázaro J, Palacios Colom L. Reacciones adversas a los AINE: Alergia, intolerancia. Tratado de Alergia. Ergon. 2007 vol II. Cap.73, p1461-81.

36. Kowalski ML, Makowska JS, Blanca M, Bavbek S, Bochenek G, Bousquet J, et al. Hypersensitivity to nonsteroidal antiinflammatory drugs (NSAIDs) classification, diagnosis and management: review of the EAACI/ENDA and GA2LEN/ HANNA. Allergy. 2011;66:818-29.

37. Williams AN. Diagnostic Evaluation in Aspirin-Exacerbated Respiratory Disease. Immunol Allergy Clin North Am. 2016. 36:657-68.

38. White AA, Stevenson DD. Aspirin desensitization in aspirinexacerbated respiratory disease. Immunol Allergy Clin North Am. 2013;33:211-22.

39. Aberer W, Bircher A, Romano A, Blanca M, Campi P, Fernandez $J$, et al. Drug provocation testing in the diagnosis of drug hypersensitivity reactions: general considerations. Allergy. 2003;58:854-63.

40. Macy E, Bernstein JA, Castells MC, Gawchik SM, Lee TH, Settipane RA, et al. Aspirin challenge and desensitization for aspirin-exacerbated respiratory disease: a practice paper. Ann Allergy Asthma Immunol. 2007;98:172-4.

41. Blais CM, Davis BE, Cockcroft DW. Duration of bronchoprotection of the long-acting muscarinic antagonists tiotropium \& glycopyrronium against methacholine-induced bronchoconstriction in mild asthmatics. Respiratory medicine. 2016;118:96-101.

42. Berges-Gimeno MP, Simon RA, Stevenson DD. The effect of leukotriene-modifier drugs on aspirin-induced asthma and rhinitis reactions. Clin Exp Allergy. 2002;32:1491-6.

43. White AA, Stevenson DD, Simon RA, The blocking effect of essential controller medications during aspirin challenges in patients with aspirin-exacerbated respiratory disease. Ann Allergy Asthma Immunol. 2005;95:330-5.

44. White A, Ludington E, Mehra P, Stevenson DD, Simon RA. Effect of leukotriene modifier drugs on the safety of oral aspirin challenges. Ann Allergy Asthma Immunol. 2006;97:688-93.

45. Bobolea I, Barranco P, Fiandor A, Cabañas R, Quirce $S$. Omalizumab: a potential new therapeutic approach for aspirin-exacerbated respiratory disease. J Investig Allergol Clin Immunol. 2010;20:448-9.

46. Phillips-Angles E, Barranco P, Lluch-Bernal M, DominguezOrtega J, López-Carrasco V, Quirce S. Aspirin tolerance in patients with nonsteroidal anti-inflammatory drugexacerbated respiratory disease following treatment with omalizumab. The J Allergy Clin Immunol Pract. 2017;5:,842-5.

47. Davila Gonzalez I, Moreno Benitez F, Quirce S. Benralizumab: A New Approach for the Treatment of Severe Eosinophilic Asthma. J Investig Allergol Clin Immunol. 2019;29:84-93.

48. Coates AL, Wanger J, Cockcroft DW, Culver BH and Bronchoprovocation Testing Task Force. ERS technical standard on bronchial challenge testing: general considerations and performance of methacholine challenge tests. Eur Resp J 2017:49:1601526

49. Hope AP, Woessner KA, Simon RA, Stevenson DD. Rational approach to aspirin dosing during oral challenges and 
desensitization of patients with aspirin-exacerbated respiratory disease. J Allergy Clin Immunol. 2009;123:406-10.

50. Chen JR, Buchmiller BL, Khan DA. An Hourly Dose-Escalation Desensitization Protocol for Aspirin-Exacerbated Respiratory Disease. J Allergy Clin Immunol Pract. 2015;3:926-31.

51. Morales DR, Guthrie B, Lipworth BJ, Jackson C, Donnan PT, Santiago VH. NSAID-exacerbated respiratory disease: a metaanalysis evaluating prevalence, mean provocative dose of aspirin and increased asthma morbidity. Allergy. 2015;70:828-35.

52. Williams AN, Simon RA, Woessner KM, Stevenson DD. The relationship between historical aspirin-induced asthma and severity of asthma induced during oral aspirin challenges. J Allergy Clin Immunol. 2007;120:273-7.

53. Kowalski ML, Asero R, Bavbek S, Blanca M, Blanca-Lopez N, Bochenek $G$, et al. Classification and practical approach to the diagnosis and management of hypersensitivity to nonsteroidal anti-inflammatory drugs. Allergy. 2013;68:1219-32.

54. Lee RU, Stevenson DD. Aspirin-exacerbated respiratory disease: evaluation and management. Allergy Asthma Immunol Res. 2011;3:3-10.

55. Daffern PJ, Muilenburg D, Hugli TE, Stevenson DD. Association of urinary leukotriene E4 excretion during aspirin challenges with severity of respiratory responses. J Allergy Clin Immunol. 1999;104(3 Pt 1):559-64.

56. Lieberman P, Nicklas RA, Oppenheimer J, Kemo SF, Lang DM, Bernstein DI, et al. The diagnosis and management of anaphylaxis practice parameter: 2010 update. J Allergy Clin Immunol. 2010;126:477-80.

57. Greenhawt M, Gupta RS, Meadows JA, Pistiner M, Spergel JM, Camargo CA Jr, et al. Guiding Principles for the Recognition, Diagnosis and Management of Infants with Anaphylaxis: An Expert Panel Consensus. J Allergy Clin Immunol Pract. 2019;7:1148-56.

58. Cardona Dahl V; Grupo de trabajo de la Guía GALAXIA de actuación en anafilaxia. [Guideline for the management of anaphylaxis]. Med Clin (Barc). 2011;136:349-55.

59. Zambonino MA, Torres MJ, Muñoz C, Requena G, Mayorga C, Posadas T, et al. Drug provocation tests in the diagnosis of hypersensitivity reactions to non-steroidal anti-inflammatory drugs in children. Pediatr Allergy Immunol. 2013 24(2):151-9.

60. Bou R. Enfermedad de Kawasaki. Protoc Diagn Ter Pediatr. 2014;1:117-29.

61. Agencia Española de Medicamentos y Productos Sanitarios. AEMPS. Medicamentos de uso humano. http://www.aemps. gob.es/cima/ fichas Técnicas.

62. Benahmed S, Picot MC, Dumas F, Demoly P. Accuracy of a pharmacovigilance algorithm in diagnosing drug hypersensitivity reactions. Arch Intern Med. 2005;165:1500-5.

63. Blanca-López N, Cornejo-García JA, Plaza-Serón MC, Doña I, Torres-Jaén MJ, Canto G, et al. Hypersensitivity to Nonsteroidal Anti-inflammatory Drugs in Children and Adolescents: CrossIntolerance Reactions. J Investig Allergol Clin Immunol. 2015:25:259-69.

64. Sanchez Borges M, Capriles-Behrens E, Caballero-Fonseca F. Hypersensitivity to non-steroidal anti-inflammatory drugs in childhood. Pediatr Allergy Immunol. 2004;15:376-80.

65. Rubio M, Bousquet PJ, Gomes E, Romano A, Demoly P. Results of drug hypersensitivity evaluations in a large group of children and adults. Clin Exp Allergy. 2012;42:123-30.
66. Rathmell J, Viscomi C, Ashburn M. Management of NonObstetric Pain during Pregnancy and Lactation. Anesth Analg. 1997;85:1074-87

67. Li DK, Liu L. Odouli R. Exposure to non-steroidal antiinflammatory drugs during pregnancy and risk of miscarriage: population based cohort study. BMJ. 2003;327:368-72.

68. Yarrington CD, Valente AM, Economy KE. Cardiovascular Management in Pregnancy. Antithrombotic Agents and Antiplatelet Agents. Circulation. 2015;132:1354-64.

69. Simons FE, Schatz M. Anaphylaxis during pregnancy. J Allergy Clin Immunol. 2012;130:597-606.

70. Alijotas-Reig J, Miguel-Moncin MS, Cistero-Bahima A. Aspirin desensitization in the treatment of antiphospholipid syndrome during pregnancy in ASA-sensitive patients. Am J Reprod Immunol. 2006;55:45-50.

71. Nizankowska E, Bestynska-Krypel A, Cmiel A, Szczeklik A. Oral and bronchial provocation tests with aspirin for diagnosis of aspirin-induced asthma. Eur Respir J. 2000;15:863-9.

72. Dahlen B, Zetterstöm 0. Comparation of bronchial and per oral provocation with aspirin in aspirin-sensitive asthmatics. Eur Respir J. 1990;3:527-34.

73. Barranco P, Bobolea I, Larco JI, Prior N, Lopez-Serrano MC, Quirce S. Diagnosis of aspirin-induced asthma combining the bronchial and the oral Challenge tests: a preliminary study. J Investig Allergol Clin Immunol. 2009;19:446-52.

74. Bianco S, Robuschi M, Petrioni G. Aspirin-induced tolerance in aspirin-induced asthma detected by a new challenge. (IRCS) Med Sci. 1977;5:129-37.

75. Philips GD, Focard R, Holgate ST. Inhaled lysine-aspirin as a bronchoprovocation procedure in aspirin-sensitive asthma. Its repeatability, absence of late-phase reaction and the role of histamine. J Allergy Clin Immunol. 1989;84:232-41.

76. Park HS. Early and late onset asthmatic responses following lysine-aspirin inhalation in aspirin-sensitive asthmatic patients. Clin Exp Allergy. 1995;25:38-40.

77. Melillo G, Padovano A, Cocco G, Masi C. Dosimeter inhalation test with lysine acetylsalicylate for the detection of aspirininduced asthma. Ann Allergy. 1993;71:61-3.

78. Melillo G, Balzano G, Bainco S, Dahlén B. Oral and inhalation provocation tests for the diagnosis of aspirin-induced asthma. Report of Interasma Working Group on Standardization of Inhalation Provocation Tests in Aspirin-Induced Asthma. Allergy. 2001;56:899-911.

79. Bachert C, Gonsior E, Berdel D. Richtlinien für die Durchfürung von nasalen Provokationen mit Allergen bei Erkrangungen der oberen Luftwege. Allergologie. 1990;13:53-6.

80. Druce HM, Schumacher MJ. Nasal provocation challenge. The Committee on Upper Airway Allergy. J Allergy Clin Immunol. 1990;86:261-4.

81. Schumacher MJ. Nasal provocation test. Rhinology. 1992; 14:242-6.

82. Lund VJ, Aaronson D, Bousquet J, Dahl R, Davies RJ, Durham $S R$, et al. International Consensus Report on the diagnosis and management of rhinitis. International Rhinitis Management Working Group. Allergy. 1994;49:1-34.

83. Melillo G, Bonini S, Cocco G, Davies RJ, de Monchy JGR, Frolund $L$, et al. EAACl provocation tests with allergens. Report prepared by the European Academy of Allergology and 
Clinical Immunology Subcommittee on provocation tests with allergens. Allergy. 1997;52:1-35.

84. Malm L, Gerth Van Wijk R, Bachert C. Guidelines for nasal provocations with aspects on nasal patency, airflow, and airflow resistance. International Committee on Objective Assessment of the Nasal Airways, International Rhinologic Society. Rhinology. 2000;38:1-6.

85. Litvyakova LI, Baraniuk JN. Nasal provocation testing: a review. Ann Allergy Asthma Immunol. 2001;86:355-65.

86. Litvyakova LI, Baraniuk JN. Human nasal allergen provocation for determination of true allergic rhinitis: methods for clinicians. Curr Allergy Asthma Rep. 2002;2:194-202.

87. Gosepath J, Amedee RG, Mann WJ. Nasal provocation testing as an international standard for evaluation of allergic and nonallergic rhinitis. Laryngoscope. 2005;115:512-6.

88. Dordal MT, Lluch-Bernal M, Sánchez MC, Rondón C, Navarro A, Montoro J, et al. SEAIC Rhinoconjunctivitis Committee. Allergen-specific nasal provocation testing: review by the rhinoconjunctivitis committee of the Spanish Society of Allergy and Clinical Immunology. J Investig Allergol Clin Immunol. 2011;21:1-12.

89. Augé J, Vent J, Agache I, Airaksinen L, Campo Mozo P, Chaker $A$, et al. EAACI Position paper on the standardization of nasal allergen challenges. Allergy. 2018;73:1597-1608.

90. Cimarra $M$, Robledo T. Aplicación en provocación nasal específica. In: Valero A, Fabra JM, Márquez F, Orus C, Picado C, Sastre J, Sierra JI editors. Manual de rinomanometría acústica. Barcelona: MRA Médica; 2001. p. 55-63.

91. Lee RU, White $A A$, Ding $D$, Dursun $A B$, Woessner KM, Simon $R A$, et al. Use of intranasal ketorolac and modified oral aspirin challenge for desensitization of aspirin-exacerbated respiratory disease. Ann Allergy Asthma Immunol. 2010;105:130-5.

92. Quiralte-Castillo J, Ávila-Castellano MR, Cimbollek S, Benaixa P, Leguisamo S, Baynova K, et al. Nasal Ketorolac Challenge Using Acoustic Rhinometry in Patients With AspirinExacerbated Respiratory Disease. J Investig Allergol Clin Immunol. 2017;27:169-74.

93. Clement PAR, Gordts F. Standardisation Committee on Objective Assessment of the Nasal Airway, IRS, and ERS. Consensus report on acoustic rhinometry and rhinomanometry. Rhinology. 2005;43:169-79.

94. Eccles R.A guide to practical aspects of measurement of human nasal airflow by rhinomanometry. Rhinology. 2011;49:2-10.

95. Pawlowicz A, Williams WR, Davies BH. Inhalation and nasal challenge in the diagnosis of aspirin induced asthma. Allergy. 1991;46:405-9.
96. González-Pérez R, Vives R, Poza-Guedes P, Campo P, Merchán $R$, Lozoya $C$, et al. Nasal provocation test with lysine-aspirine in the diagnosis of NSAIDs intolerance with respiratory symptoms. Allergy. 2001;56:104.

97. González-Pérez R, Vives R, Poza-Guedes P, Merchán R, Cimbollek $S$, Rodríguez J. Nasal provocation test with LysineAcetylsalicylate in the diagnosis of NSAIDs Intolerance with Respiratory symptoms. J Allergy Clin Immunol. 2002;109:2689.

98. Alonso-Llamazares A, Martínez-Cócera C, Domínguez-Ortega J, Robledo-Echarren T, Cimarra-Alvarez M, Mesa del Castillo M. Nasal provocation test (NPT) with aspirin: a sensitive and safe method to diagnose aspirin-induced asthma (AIA). Allergy. 2002;57:632-5.

99. Muñoz-Cano R, Bartra J, Sanchez-Lopez J, Picado C, Bissinger I, Valero A. Acoustic rhinometry and aspirin nasal challenge in the diagnosis of aspirin-intolerant asthma: clinical finding and safety aspects. Int Arch Allergy Immunol. 2013;160:307-12.

100. Uzzaman A, Metcalfe DD, Komarow HD. Acoustic rhinometry in the practice of allergy. Ann Allergy Asthma Immunol. 2006:97:745-51.

101. Casadevall J, Ventura PJ, Mullol J, Picado C. Intranasal challenge with aspirin in the diagnosis of aspirin intolerant asthma: evaluation of nasal response by acoustic rhinometry. Thorax. 2000;55:921-24.

102. Demirbas D, Cingi C, Çakli H, Kaya E. Use of rhinomanometry in common rhinologic disorders. Expert Rev Med Devices. 2011;8:769-77.

103. Basterra Alegría J, Armengot Carceller M. Exploración clínica y por imagen. Pruebas funcionales en rinología. In: Elsevier, editor. Tratado de otorrinolaringología y patología cervicofacial. 1a edición. Barcelona: MASSON; 2009.289-300.

104. Pepper AN, Ledford DK. Nasal and ocular challenges. J Allergy Clin Immunol. 2018;141:1570-7.

- Manuscript received June 8, 2019; accepted for publication September 8, 2019.

\section{- Adriana Izquierdo-Domínguez}

E-mail: adrianaeizquierdo@hotmail.com 